\title{
Dampak Insentif Fiskal terhadap Pendanaan Riset dan Pengembangan di ASEAN-5 dan Empat Negara Utama Asia
}

\author{
Nailul Huda ${ }^{\mathrm{a}, *}$ \\ ${ }^{a}$ Magister Perencanaan dan Kebijakan Publik Universitas Indonesia $\mathcal{E}$ \\ Institute for Development of Economics and Finance (INDEF)
}

\begin{abstract}
The role of innovation and technology is significant in the development of a country. At present, almost all countries compete in increasing innovation and technology. However, high costs are an obstacle to its adoption and development. Therefore, government intervention is needed, one of which is through tax incentives in research and development. This study aims to examine tax incentive policies to increase research and development funds in ASEAN and other large Asian countries. By using panel data methods and differences-in-differences, this study found insignificant effect of tax incentive policies on the research and development funds. The reason is that there are other more important determinants and unfavorable political intervention in research and development policies.
\end{abstract}

Keywords: fiscal incentives; research and development; panel data; difference in difference

\begin{abstract}
Abstrak
Peran inovasi dan teknologi makin besar dalam perekonomian sebuah negara. Saat ini hampir seluruh negara bersaing dalam meningkatkan inovasi dan teknologi. Namun demikian, biaya yang mahal menjadi penghambat peningkatan kapasitas inovasi dan teknologi. Maka dari itu, dibutuhkan intervensi pemerintah, salah satunya melalu insentif perpajakan di bidang riset dan pengembangan. Penelitian ini ingin menjawab pertanyaan apakah kebijakan insentif perpajakan mampu meningkatkan dana riset dan pengembangan di ASEAN dan empat negara besar Asia. Dengan menggunakan metode panel data estimation dan difference-in-difference, penelitian ini menemukan fakta bahwa tidak ada pengaruh yang signifikan dari kebijakan insentif perpajakan terhadap dana riset dan pengembangan. Terdapat variabel lain di luar model yang lebih berpengaruh dan intervensi politik dalam penentuan kebijakan insentif perpajakan.
\end{abstract}

Kata Kunci: insentif fiskal; riset dan pembangunan; data panel; difference in difference Kode Klasifikasi JEL: H25; O32

*Alamat Korespondensi Penulis: Jln. Batu Merah No. 45, RT. 3/RW. 2, Pejaten Timur, Kecamatan Pasar Minggu, Kota Jakarta Selatan, Daerah Khusus Ibukota Jakarta 12510. E-mail: nailul30@gmail. com; nailul.huda@indef.or.id. 


\section{Pendahuluan}

Dalam beberapa tahun terakhir, peran inovasi dan teknologi dalam mendorong pertumbuhan ekonomi makin meningkat. Gagasan inovasi dan teknologi dalam mendorong produksi nasional sudah diungkapkan oleh Solow (1956) yang menyebut pengembangan teknologi merupakan faktor esensial untuk mendorong pertumbuhan ekonomi. Coccia (2011) mengungkapkan inovasi dan teknologi, termasuk penelitian dan pengembangan (litbang), menjadi pendorong produktivitas ekonomi nasional. Rakgotho (2018) juga mengungkapkan inovasi dan teknologi merupakan jantung dari pertumbuhan ekonomi.

Dalam studi mereka di 27 negara Uni Eropa, Freimane dan Bāliņa (2016) menemukan bahwa pengeluaran R\&D menimbulkan dampak signifikan terhadap pertumbuhan ekonomi dalam PDB riil per orang. Studi mereka menunjukkan bahwa peningkatan 10 persen dalam intensitas R\&D akan menghasilkan peningkatan 0,2 persen untuk pertumbuhan ekonomi mereka dalam jangka pendek. Dengan berfokus pada analisis historis, Yang dan Han (2017) meneliti apakah meningkatkan kegiatan penelitian akan meningkatkan pertumbuhan ekonomi di Tiongkok. Untuk meningkatkan penelitian dan inovasinya di tingkat nasional, Cina membentuk badan-badan terkait penelitian dan inovasi dan telah dilakukan sejak reformasi dan dibuka pada akhir 1970-an. Yang dan Han berpendapat bahwa implementasi penelitian di Cina mungkin tidak selalu menguntungkan pertumbuhan ekonomi. Akcali dan Sismanoglu (2015) juga mendukung premis yang sama bahwa peningkatan pengeluaran litbang memiliki dampak signifikan terhadap pertumbuhan ekonomi negara.

Dibandingkan dengan negara ASEAN dan empat negara utama Asia (Korea Selatan, Cina, Jepang, dan India), rasio dana R\&D terhadap PDB masih relatif sangat rendah. Pada 2017, porsi R\&D hanya 0,24 persen dari PDB. Angka tersebut masih sangat kecil dibandingkan dengan Korea Selatan, Jepang, Cina, India, serta negara-negara tetangga. Korea Selatan mempunyai rasio pengeluaran $R \& D$ terhadap PDB sebesar 4,55 persen. Maka dari itu, perkembangan ekspor barangbarang dengan teknologi tinggi sangat besar di Korea Selatan. Perusahaan seperti Samsung mampu menjadi pemimpin di pangsa ponsel pintar di dunia. Begitu juga dengan Cina yang akhir-akhir ini mengembangkan inovasi dan teknologinya. Porsi rasio pengeluaran R\&D terhadap PDB di China mencapai 2,13 persen. Dampaknya produk-produk berteknologi dari Cina bisa diekspor ke seluruh dunia termasuk perusahaan-perusahaan ponsel dari Cina seperti Xiaomi dan Huawei.

Dalam pembangunan rasio pengeluaran $R \& D$ terhadap PDB, masing-masing negara mempunyai strategi masing-masing. Rakgotho (2018) juga menyebutkan bahwa pengembangan R\&D mempunyai jangka waktu yang panjang dan mahal, maka dibutuhkan intervensi dari pemerintah. Salah satu intervensinya adalah pemberian insentif pajak di bidang R\&D. Cina mempunyai tiga strategi, yaitu super deduction tax incentives, reduced tax rates, dan tax allowance. Super deduction tax incentives merupakan strategi insentif pajak yang paling banyak digunakan. 


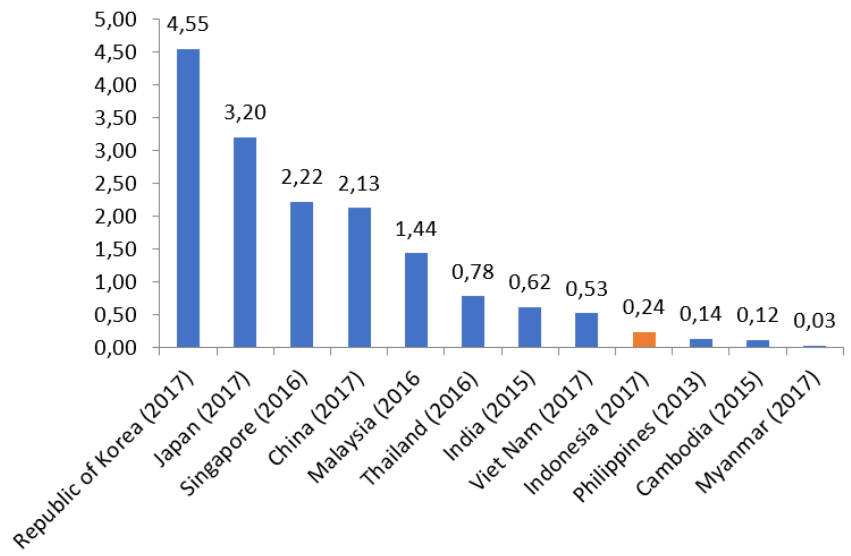

\section{Gambar 1: Perbandingan Rasio Pengeluaran Riset dan Pengembangan (R\&D) terhadap PDB di ASEAN dan Empat Negara Utama Asia Sumber: UNESCO Institute for Statistics}

Setidaknya ada Cina, India, Malaysia, dan Singapura yang menggunakan strategi ini. Sedangkan Thailand menggunakan strategi deduction tax incentives dimana pemberian insentifnya lebih kecil dari super deduction tax incentives. Indonesia sendiri hanya memiliki kebijakan tax credits yang sebelumnya pada tahun 2019 mempunyai kebijakan super tax deductions.

Tabel 1: Perbandingan Kebijakan Insentif Perpajakan di Bidang Riset dan Pengembangan

\begin{tabular}{|c|c|c|c|c|c|c|c|}
\hline Type of Incentives & China India & Japan & $\begin{array}{l}\text { South } \\
\text { Korea }\end{array}$ & Indonesia & Malaysia & Singapore Thailand & $\begin{array}{l}\text { Viet } \\
\text { Nam }\end{array}$ \\
\hline Super Tax Deductions & $\mathrm{V}$ & & & & $\mathrm{v}$ & $\mathrm{V}$ & \\
\hline Tax Deductions & & & & & & $\mathrm{v}$ & \\
\hline Reduced Tax Rates & $\mathrm{v}$ & & & & & & $\mathrm{v}$ \\
\hline Tax Credits & $\mathrm{V}$ & $\mathrm{v}$ & $\mathrm{v}$ & & & & \\
\hline Tax Allowance & $\mathrm{v}$ & & & $\mathrm{V}$ & $\mathrm{V}$ & & $\mathrm{v}$ \\
\hline
\end{tabular}

Negara-negara dengan kebijakan insentif perpajakan di bidang R\&D mempunyai rasio dana R\&D terhadap PDB lebih besar dibandingkan dengan negara yang tidak mempunyai kebijakan yang sama. Jia dan Ma (2017) mengungkapkan insentif pajak dapat menurunkan beban administrasi perusahaan untuk melakukan riset dan pengembangan.

Hasil penelitian dari Bozio et al. (2014) mengungkapkan ada pengaruh positif dan signifikan dari kebijakan insentif fiskal berupa tax credit terhadap investasi R\&D. Hasil yang sama juga ditemukan oleh Guceri (2018), Lee et al. (2011), dan Hægeland dan Møen (2007). Pada penelitian lebih lanjut, Jia dan Ma (2017) mengungkapkan bawah insentif pajak hanya akan efektif dan berdampak signi- 
fikan kepada perusahaan swasta. Pada perusahaan milik negara, insentif pajak pengaruhnya kecil terhadap pengeluaran R\&D.

Negara-negara utama ASEAN (Indonesia, Malaysia, Thailand, Singapura, dan Viet Nam) dan empat negara utama Asia (Jepang, Cina, India, dan Korea Selatan) mempunyai rasio terhadap PDB dunia sebesar 30 persen (World Bank, 2019). Maka sangat menarik jika kita melihat pengaruh dari kebijakan insentif fiskal berupa insentif perpajakan di bidang $R \& D$ dalam mendorong rasio dana $R \& D$ terhadap PDB sehingga R\&D mendorong pertumbuhan ekonomi, terutama pada negara-negara ASEAN dan empat negara utama Asia dimana bisa menjadi pusat ekonomi baru dunia. Paper-paper sebelumnya juga membahas dampak pada masing-masing negara secara parsial. Maka paper ini akan berkontribusi dalam menjawab bagaimana pengaruh insentif perpajakan di bidang R\&D terhadap pendanaan R\&D di ASEAN 5 dan empat negara utama Asia.

\section{Metode Penelitian}

Paper ini menggunakan metode data panel dengan sampel 9 negara dengan rentang waktu sampel adalah 20 tahun (1998-2017). Variabel dan sumber data dari paper ini adalah:

- Rasio dana R\&D terhadap PDB

Data bersumber dari The United Nations Educational, Scientific and Cultural Organisation (UNESCO).

- Dummy kebijakan insentif perpajakan

Data bersumber dari beberapa dokumen organisasi regional atau masingmasing negara, contohnya OECD (2018), KPMG (2015), dan Ernst \& Young (2018).

- Pertumbuhan Ekonomi, Rasio Investasi terhadap PDB, Rasio FDI terhadap PDB, Jumlah Paten berdasarkan Penduduk Setempat, Jumlah Paten berdasarkan Bukan Penduduk Setempat

Data variabel-variabel tersebut bersumber dari World Bank (2019).

- Total Faktor Produksi, Kontribusi Kuantitas Output Seluruh Tenaga Kerja terhadap PDB, Kontribusi Kualiitas Output Seluruh Tenaga Kerja terhadap PDB

Data variabel-variabel di atas bersumber dari The Conference Board (TCB).

Model yang digunakan paper ini adalah Pooled Least Square (PLS), Fixed Effect Model (FEM), dan Random Effect Model (REM). Dengan menggunakan metode chow test dan hausman test, paper ini akan memilih model yang paling robust.

Model estimasi yang digunakan dalam penelitian ini adalah:

$$
\begin{aligned}
& R \& D E x p e n_{-} t t_{-} G D P_{i t}=\alpha_{0}+\alpha_{1} d u m m y \_t a x \_i n c_{-} o n_{-} r n d \_G D P_{i t} \\
& +\alpha_{2} G D P \_G r o w t h h_{i t}+\alpha_{3} I_{-} t_{-} G D P_{i t}+\alpha_{4} F D I \_t o \_G D P_{i t} \\
& +\alpha_{5} \text { Patent_Residence }_{i t}+\alpha_{6} \text { Patent_nonResidence }_{i t} \\
& +\alpha_{7} \text { TFP }_{i t}+\alpha_{8} \text { LaborQuantity_to_GDP } \\
& +\alpha_{9} \text { LaborQuality_to_GDP } P_{i t}+\varepsilon_{i t}
\end{aligned}
$$


dengan:

$R \& D$ expen_to_GDP $P_{i t}$ : rasio dana R\&D terhadap PDB negara $i$ pada tahun $t$;

Dummy_tax_inc_on_rnd $d_{i t}:$ Dummy Kebijakan Insentif Perpajakan negara $i$ pada tahun $t$;

GDP_Growth $h_{i t}$ : pertumbuhan ekonomi negara $i$ pada tahun $t$;

$I_{-} t o \_G D P_{i t}:$ rasio investasi terhadap PDB negara $i$ pada tahun $t$;

FDI_to_GDP $P_{i t}$ : rasio FDI terhadap PDB negara $i$ pada tahun $t$;

Patent_Residence ${ }_{i t}$ : jumlah paten berdasarkan penduduk setempat negara $i$ pada tahun $t$;

Patent_nonResidence $_{i t}$ : jumlah paten berdasarkan bukan penduduk setempat negara $i$ pada tahun $t$;

$T_{F P}$ it : Total Faktor Produksi negara $i$ pada tahun $t$;

LaborQuantity_to_GDP : kontribusi kuantitas output seluruh tenaga kerja ke PDB negara $i$ pada tahun $t$;

LaborQuality_to_GDP : kontribusi kuantitas output tenaga kerja terampil ke PDB negara $i$ pada tahun $t$.

Selain menggunakan analisis regresi, penelitian ini juga menggunakan pendekatan difference in difference (DID). DID sendiri merupakan perbandingan variabel treatment dan variabel kontrol dengan jangka waktu sebelum dan setelah mendapatkan program. Metode ini menggabungkan model perbandingan sebelumsesudah dan model perbandingan penerima dan bukan penerima. Model ini termasuk dalam kategori model evaluasi dengan data panel.

Penghitungan difference in difference (DID) menggunakan pendekatan kotak, yaitu dengan menghitung nilai dampak dari kedua beneficiaries (langsung dan tidak langsung) di awal dan di akhir program dengan dibagi ke dalam dua kelompok, yaitu treatment dan kontrol. Lebih jelasnya dapat dilihat ke dalam tabel berikut :

Tabel 2: Estimasi DiD

\begin{tabular}{lll}
\hline \hline & $\begin{array}{l}\text { Negara dengan Kebijakan Insentif } \\
\text { Pajak (Tr) }\end{array}$ & $\begin{array}{l}\text { Negara tidak ada Kebijakan Insentif } \\
\text { Pajak }(\mathrm{Ct})\end{array}$ \\
\hline Setelah Program & $Y_{1}\left(u_{i}\right) \mid D_{i}=1$ & $Y_{1}\left(u_{i}\right) \mid D_{i}=0$ \\
Sebelum Program & $Y_{0}\left(u_{i}\right) \mid D_{i}=1$ & $Y_{0}\left(u_{i}\right) \mid D_{i}=0$ \\
Difference & $\left(Y_{1}\left(u_{i}\right) \mid D_{i}=1\right)-\left(Y_{0}\left(u_{i}\right) \mid D_{i}=1\right)$ & $\left(Y_{1}\left(u_{i}\right) \mid D_{i}=0\right)-\left(Y_{0}\left(u_{i}\right) \mid D_{i}=0\right)$ \\
\hline
\end{tabular}

Maka, dapat digunakan rumus DID sebagai berikut:

$$
D I D=\left[\left(Y_{1}\left(u_{i}\right) \mid D_{i}=1\right)-\left(Y_{0}\left(u_{i}\right) \mid D_{i}=1\right)\right]-\left[\left(Y_{1}\left(u_{i}\right) \mid D_{i}=0\right)-\left(Y_{0}\left(u_{i}\right) \mid D_{i}=0\right)\right]
$$

Setelah dilakukan penghitungan DID, maka perbedaan antara nilai variabel treatment dan kontrol merupakan hasil dari kebijakan insentif perpajakan di bidang R\&D. Apabila nilai akhir nilai variabel treatment lebih tinggi daripada variabel kontrol maka bisa dikatakan kebijakan tersebut efektif. 


\section{Hasil}

\subsection{Hasil Estimasi}

Berdasarkan Gambar 2, Indonesia masuk dalam golongan negara dengan pertumbuhan ekonomi dan rasio dana R\&D terhadap GDP yang relatif rendah dibandingkan negara ASEAN dan empat negara utama Asia. Cina mempunyai pertumbuhan ekonomi yang relatif tinggi dengan dana R\&D yang cukup besar. Jepang, Korea Selatan, dan Singapura meskipun pertumbuhan ekonominya cenderung rendah, namun tiga negara tersebut mempunyai proporsi dana R\&D yang cukup besar. Malaysia dan Thailand juga akan mengikuti Jepang, Korea Selatan, dan Singapura. India, Filipina, dan Viet Nam mempunyai potensi untuk mengikuti perkembangan dari Cina.

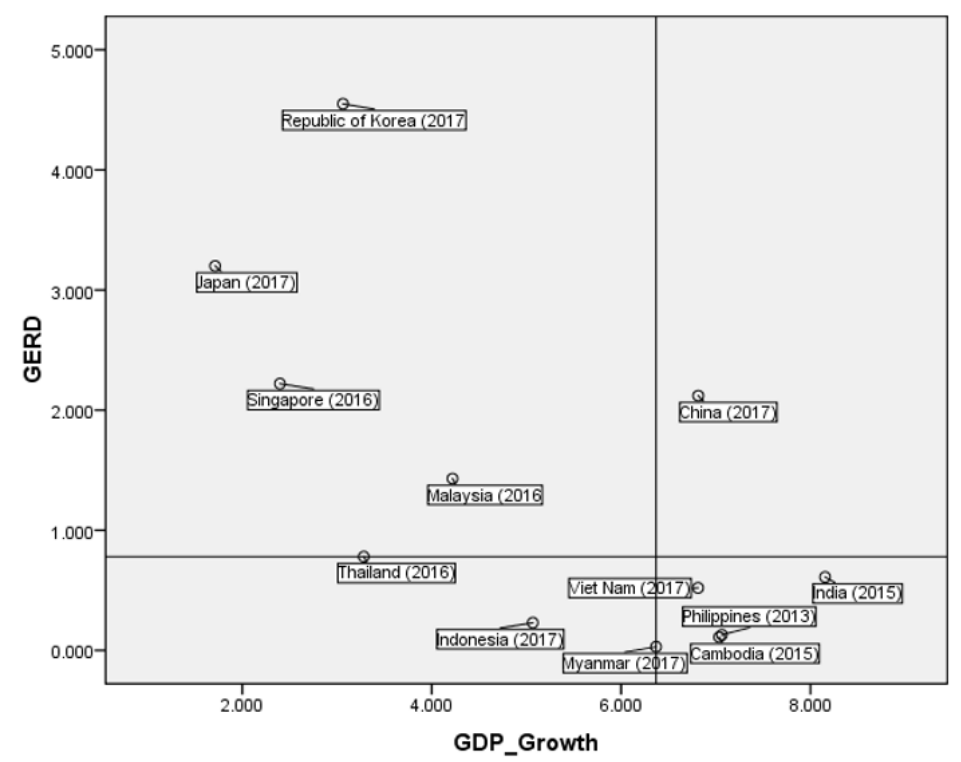

Gambar 2: Perbandingan Rasio Dana R\&D terhadap PDB dan Pertumbuhan Ekonomi

Dengan menggunakan metode Chaw Test dan LM Test, penelitian ini lebih tepat menggunakan model PLS dibandingkan dua model lainnya. Tidak ada perbedaan yang signifikan pada hasil estimasi ketiga model panel data. Berdasarkan hasil estimasi dengan menggunakan tiga metode panel (Pooled Least Square, Fixed Effect Model, dan Random Effect Model), hasil paper ini adalah insentif fiskal berpengaruh positif dan signifikan terhadap rasio dana R\&D terhadap PDB pada taraf keyakinan 99 persen. Arti dari hasil estimasi ini adalah apabila negara yang mempunyai insentif perpajakan, maka nilai rasio dana R\&D terhadap PDB akan makin besar. 
Negara -seperti Jepang dan Korea Selatan sudah mempunyai kebijakan terkait insentif perpajakan untuk kegiatan R\&D sejak tahun 1998 dengan sistem kredit perpajakan. Sedangkan Cina mempunyai begitu banyak kebijakan insentif perpajakan, namun baru mulai gencar pada tahun 2008. Sedangkan Indonesia sendiri tidak ada pajak super besar bagi perusahaan atau instansi yang melakukan R\&D.

Tabel 3: Estimasi DiD

\begin{tabular}{|c|c|c|c|}
\hline R\&D to GDP & $\overline{P L S}$ & $\overline{\mathrm{FE}}$ & $\overline{\mathrm{RE}}$ \\
\hline dummy_taxincentive & $\begin{array}{c}1.242^{* * *} \\
(0.172)\end{array}$ & $\begin{array}{c}1.355^{* * *} \\
(0.204)\end{array}$ & $\begin{array}{c}1.242^{* * *} \\
(0.172)\end{array}$ \\
\hline gdp_growth & $\begin{array}{c}-0.164^{* * *} \\
(0.0608)\end{array}$ & $\begin{array}{l}-0.140^{* *} \\
(0.0678)\end{array}$ & $\begin{array}{c}-0.164^{* * *} \\
(0.0608)\end{array}$ \\
\hline investasi_to_gdp & $\begin{array}{l}-0.0339 * \\
(0.0195)\end{array}$ & $\begin{array}{l}-0.0366^{*} \\
(0.0218)\end{array}$ & $\begin{array}{l}-0.0339 * \\
(0.0195)\end{array}$ \\
\hline fdi_to_gdp & $\begin{array}{c}0.0573^{* * *} \\
(0.0123)\end{array}$ & $\begin{array}{c}0.0594^{* * *} \\
(0.0133)\end{array}$ & $\begin{array}{c}0.0573^{* * *} \\
(0.0123)\end{array}$ \\
\hline patent_resident & $\begin{array}{l}-0.00000159^{* *} \\
(0.000000628)\end{array}$ & $\begin{array}{c}-0.00000184^{* *} \\
(0.000000718)\end{array}$ & $\begin{array}{l}-0.00000159^{* *} \\
(0.000000628)\end{array}$ \\
\hline patent_nonresident & $\begin{array}{l}0.0000239^{* * *} \\
(0.00000586)\end{array}$ & $\begin{array}{l}0.0000264^{* * *} \\
(0.00000679)\end{array}$ & $\begin{array}{l}0.0000239 * * * \\
(0.00000586)\end{array}$ \\
\hline $\operatorname{tfp}$ & $\begin{array}{c}0.0795 \\
(0.0675)\end{array}$ & $\begin{array}{c}0.0173 \\
(0.0797)\end{array}$ & $\begin{array}{c}0.0795 \\
(0.0675)\end{array}$ \\
\hline laborquantity_to_gdp & $\begin{array}{c}0.199 * * \\
(0.0963)\end{array}$ & $\begin{array}{c}0.159 \\
(0.109)\end{array}$ & $\begin{array}{c}0.199 * * \\
(0.0963)\end{array}$ \\
\hline laborquality_to_gdp & $\begin{array}{c}-0.322 \\
(0.212)\end{array}$ & $\begin{array}{c}-0.35 \\
(0.241)\end{array}$ & $\begin{array}{c}-0.322 \\
(0.212)\end{array}$ \\
\hline _cons & $\begin{array}{c}2.044^{* * *} \\
(0.395)\end{array}$ & $\begin{array}{c}1.988^{* * *} \\
(0.426)\end{array}$ & $\begin{array}{c}2.044^{* * *} \\
(0.395)\end{array}$ \\
\hline $\begin{array}{l}\mathrm{N} \\
\mathrm{R} 2\end{array}$ & $\begin{array}{c}131 \\
0.676\end{array}$ & $\begin{array}{c}131 \\
0.679\end{array}$ & 131 \\
\hline
\end{tabular}

Standard errors in parentheses

${ }^{*} \mathrm{p}<0.1,{ }^{* *} \mathrm{p}<0.05,{ }^{* * *} \mathrm{p}<0.01$

Setelah melakukan regresi, paper ini melakukan analisis difference in difference (DID) untuk melihat apakah benar ada efek insentif perpajakan terhadap rasio dana R\&D terhadap PDB. Hasil estimasi pada Tabel 3 dan 4 memperlihatkan bahwa kebijakan insentif perpajakan berpengaruh, namun tidak signifikan terhadap rasio dana $R \& D$ terhadap PDB pada periode dan negara sampel. Artinya perubahan, baik penurunan maupun kenaikan, rasio dana R\&D terhadap PDB bukan disebabkan oleh insentif perpajakan. Pengaruh yang signifikan bisa dari beberapa variabel lainnya yang tidak dijelaskan dalam paper ini. 
Dampak Insentif Fiskal terhadap Pendanaan Riset ...

Tabel 4: Hasil Estimasi Difference in Difference (DID)

\begin{tabular}{|c|c|c|c|c|c|c|}
\hline rnd_to_gdp & Coef. & Std. Err. & $\mathrm{t}$ & $\mathrm{P}>\mathrm{t}$ & \multicolumn{2}{|c|}{ [95\% Conf. Interval] } \\
\hline tahun & -0.0123593 & 0.0200305 & -0.62 & 0.538 & -0.0519961 & 0.0272775 \\
\hline dummy_taxincentive & -9.481 .231 & 5.599 .612 & -0.17 & 0.866 & -1.202 .874 & 101.325 \\
\hline did & 0.0055967 & 0.0278962 & 0.2 & 0.841 & -0.0496048 & 0.0607982 \\
\hline _cons & 2.567 .224 & 4.016 .824 & 0.64 & 0.524 & -5.381 .346 & 1.051 .579 \\
\hline Outcome var. & rnd_tñ & S. Err & $\mathrm{t}$ & $\mathrm{P}>\mathrm{t}$ & & \\
\hline Before & & & & & & \\
\hline Control & 25.672 & & & & & \\
\hline Treated & 16.191 & & & & & \\
\hline Diff $(T-C)$ & -9.481 & 55.996 & -0.17 & 0.866 & & \\
\hline After & & & & & & \\
\hline Control & 25.66 & & & & & \\
\hline Treated & 16.184 & & & & & \\
\hline Diff $(T-C)$ & -9.476 & 55.968 & 0.17 & 0.866 & & \\
\hline Diff-in-Diff & 0.006 & 0.028 & 0.2 & 0.841 & & \\
\hline
\end{tabular}

\subsection{Diskusi}

Hasil estimasi model paper ini mengungkapkan adanya hubungan positif dan signifikan antara kebijakan insentif perpajakan di bidang R\&D terhadap rasio dana R\&D terhadap PDB pada negara-negara ASEAN 5 dan 4 negara utama Asia yang menjadi sampel paper ini. Hasil ini menguatkan temuan-temuan Jia dan Ma (2017), Bozio et al. (2014), Guceri (2018), Lee et al. (2011), dan Haegeland dan Moen (2007) yang sepakat bahwa ada pengaruh dari kebijakan insentif perpajakan di bidang R\&D terhadap rasio dana R\&D terhadap PDB.

Namun demikian, dari hasil analisis difference in difference (DID) menunjukkan hasil yang sebaliknya dimana insentif perpajakan di bidang R\&D tidak berpengaruh signifikan terhadap rasio dana R\&D terhadap PDB. Artinya adalah rasio dana R\&D terhadap PDB yang berubah diperngaruhi oleh variabel lain di luar model paper. Alasan lainnya adalah insentif fiskal yang diberikan sarat dengan kepentingan politik golongan tertentu. Alasan ini didasarkan pada temuan Jia dan Ma (2017) yang menyebutkan bahwa insentif fiskal lebih berpengaruh terhadap perusahaan swasta yang bebas dari koneksi politik. Kasus ini sering terjadi pada negara berkembang.

Melihat sebagian besar negara sampel merupakan negara berkembang, maka alasan insentif fiskal yang diberikan sarat dengan kepentingan politik bisa menjadi asalan kenapa insentif perpajakan di bidang R\&D tidak berpengaruh signifikan terhadap rasio dana $R \& D$ terhadap PDB. Di Indonesia sendiri, pemberian insentif perpajakan dinilai hanya akan menguntungkan segelintir perusahaan yang memang mempunyai dana R\&D yang cukup besar. 


\section{Kesimpulan}

Meskipun hasil analisis difference in difference (DID) menunjukkan insentif perpajakan di bidang R\&D tidak berpengaruh signifikan terhadap rasio dana $R \& D$ terhadap PDB, kebijakan insentif perpajakan di bidang R\&D tetap perlu dilakukan. Hanya saja, kebijakan tersebut harus bersih dari intervensi politik kelompok tertentu. Insentif perpajakan dinilai mampu mendorong dana R\&D dan pada akhirnya mendorong pertumbuhan ekonomi. Namun, jika tidak bebas intervensi politik, maka kebijakan insentif perpajakan di bidang R\&D akan sia-sia.

Bagi dunia usaha terutama badan usaha swasta, insentif perpajakan berguna untuk meningkatkan besaran dana R\&D perusahaan. Hal tersebut disebabkan perusahaan swasta lebih terbebas dari intervensi politik pemerintah. Paper ini juga turut berkontribusi dalam penelitian tentang R\&D berdasarkan regional, dimana ke depannya kebijakan publik sebuah negara akan dipengaruhi oleh kebijakan di tingkat regional.

\section{Daftar Pustaka}

[1] Akcali, B. Y., \& Sismanoglu, E. (2015). Innovation and the effect of research and development (R\&D) expenditure on growth in some developing and developed countries. Procedia - Social and Behavioral Sciences, 195, 768-775. doi: https://doi.org/10.1016/j.sbspro.2015.06.474.

[2] Bozio, A., Irac, D., \& Py, L. (2014). Impact of research tax credit on R\&D and innovation: evidence from the 2008 French reform. EcoMod2014 6873. EcoMod. http:/ /ecomod.net/system/files/Bozio_Irac_Py_ECOMOD.pdf.

[3] Coccia, M. (2011). The interaction between public and private R\&D expenditure and national productivity. Prometheus: Critical Studies in Innovation, 29(2), 121-130. doi: https://doi.org/10.1080/08109028.2011.601079.

[4] Ernst \& Young. (2018). Worldwide RED incentives reference guide 2018. https://www.ey.com/Publication/vwLUAssets/ ey-2018-worldwide-rd-incentives-reference-guide/\$FILE/ ey-2018-worldwide-rd-incentives-reference-guide.pdf.

[5] Freimane, R., \& Bāliņa, S. (2016). Research and development expenditures and economic growth in the EU: A panel data analysis. Economics and Business, 29(1), 5-11. doi: https:/ /doi.org/10.1515/eb-2016-0016.

[6] Guceri, I. (2018). Will the real R\&D employees please stand up? Effects of tax breaks on firm-level outcomes. International Tax and Public Finance, 25(1), 1-63. doi: https://doi.org/10.1007/s10797-017-9438-3.

[7] Hægeland, T., \& Møen, J. (2007). The relationship between the Norwegian R\&D tax credit scheme and other innovation policy instruments. Reports 2007/45. Statistisk sentralbyr - Statistics Norway. https:/ / ssb.brage.unit.no/ssb-xmlui/bitstream/ handle/11250/181263/rapp_200745_en.pdf?sequence $=1$.

[8] Jia, J., \& Ma, G. (2017). Do R\&D tax incentives work? Firm-level evidence from China. China Economic Review, 46, 50-66. doi: https://doi.org/10.1016/j.chieco.2017.08.012.

[9] KPMG. (2015). RED Incentives - Adding Value Across ASPAC.

[10] Lee, Y., Kim, S., \& Lee, H. (2011). The impact of service R\&D on the performance of Korean information communication technology small and medium en- 
terprises. Journal of Engineering and Technology Management, 28(1-2), 77-92. doi: https://doi.org/10.1016/j.jengtecman.2010.12.005.

[11] The Conference Board. (2019). Total Economy Database ${ }^{\mathrm{TM}}$ Data. $\quad$ https://conference-board.org/data/economydatabase/ total-economy-database-productivity.

[12] OECD. (2018). OECD RED tax incentive database. The Organisation for Economic Co-operation and Development. https://www.oecd.org/sti/rd-tax-stats-bindexnotes.pdf.

[13] Rakgotho, C. M. (2018). South African tax incentives as a motivation for the private sector to invest in research and development (Doctoral dissertation, North-West University). https://repository.nwu.ac.za/handle/10394/31044.

[14] Solow, R. M. (1956). A contribution to the theory of economic growth. The Quarterly Journal of Economics, 70(1), 65-94. doi: https://doi.org/10.2307/1884513.

[15] World Bank. (2019). DataBank. databank.worldbank.org.

[16] Yang, P., \& Han, B. (2017). Responsible Research and Innovation and Its Implications for China. China $\mathcal{E}$ World Economy, 25(6), 120-138. doi: https://doi.org/10.1111/cwe.12224. 